\title{
Raddeanin a Suppresses Glioblastoma Growth by Inducing ROS Generation and Subsequent JNK Activation to Promote Cell Apoptosis
}

\author{
Fei Peng ${ }^{a, b} \quad$ Xiaoxiong Wang ${ }^{a, b} \quad$ Mengting Shu ${ }^{a, b} \quad$ Mingfei Yang ${ }^{a, b} \quad$ Ligang Wang ${ }^{a, b}$ \\ Zhongrui Ouyang ${ }^{a, b} \quad$ Chen Shen Xu Hou $^{a, b} \quad$ Boyan Zhao ${ }^{a, b} \quad$ Xinzhuang Wang ${ }^{a, b}$ \\ Linda Wei Zhang ${ }^{c}$ Yaohua Liua,b,d Shiguang Zhao ${ }^{a, b}$ \\ aDepartment of Neurosurgery, First Affiliated Hospital of Harbin Medical University, Harbin, ${ }^{b}$ Institute \\ of Brain Science, Harbin Medical University, Harbin, 'Shanghai Medical College, Fudan University, \\ Shanghai, dDepartment of Neurosurgery, Shanghai First People's Hospital, School of Medicine, \\ Shanghai Jiao Tong University, Shanghai, China
}

\section{Key Words}

Raddeanin A • Glioblastoma • Apoptosis • ROS/JNK signaling pathway • Autophagy

\begin{abstract}
Background/Aims: Raddeanin A (RA), an active pharmacological ingredient from Anemone raddeana Regel, plays an important role in tumor suppression. In this study, we assessed the potentially therapeutic effect of RA on glioblastoma and its underlying mechanisms. Methods: Cell viability was examined using the MTT assay. Invasive and migratory capacities were examined using Transwell and wound healing assays. Apoptosis was determined by Hoechst staining, flow cytometry, DCFH-fluorescent probe and immunohistochemical staining. Autophagy was detected by transmission electron microscopy and western blotting. A U251 glioma xenograft model was established to evaluate the effect of RA in vivo. Results: The data demonstrated that RA inhibited viability, and abrogated the invasive/migratory abilities of glioblastoma cells. In addition, RA induced apoptosis by reactive oxygen species (ROS)/ Jun N-terminal kinase (JNK) signaling in glioblastoma. Conversely, the antioxidant N-AcetylL-cysteine (NAC) and pan-caspase inhibitor z-VAD-fmk attenuated RA-induced apoptosis by scavenging ROS and inactivating caspase-3. Furthermore, the inhibition of autophagy by 3-MA exacerbated apoptosis through ROS generation and JNK phosphorylation. In vivo, RA exhibited a curative effect on U251-derived xenografts in nude mice. Conclusions: The results of this study suggest that RA suppressed the growth of glioblastoma, thus serving as a promising and potential strategy for glioblastoma chemotherapy.
\end{abstract}

F. Peng, X. Wang and M. Shu contributed equally to this work.

Shiguang Zhao and Yaohua Liu 


\section{Cellular Physiology Cell Physiol Biochem 2018;47:1108-1121 and Biochemistry Published online: May 30, $2018 \quad \begin{aligned} & \text { DOI: 10.1159/000490187 } \\ & \begin{array}{l}\text { C } 2018 \text { The Author(s). Published by S. Karger AG, Basel } \\ \text { ww.karger.com/cpb }\end{array}\end{aligned}$ \\ Peng et al.: Antitumor Effect of RA on Glioblastoma}

\section{Introduction}

Glioblastoma multiforme (GBM) is the most common and aggressive primary brain tumor in adults and has high morbidity and mortality [1]. Despite optimal treatment, the highly invasive/migratory capacity of tumor cells and difficulty in achieving complete surgical resection result in a median survival of less than two years after diagnosis [2,3]. One of the most important hallmarks of tumor cells is resistance to cell death [4]. Consequently, preferable therapeutic regimens and strategies are in urgent need to eradicate glioblastoma.

Natural products from traditional Chinese herbs used in the treatment of malignant tumors have a long history and are currently attracting increasing attention from researchers worldwide [5, 6]. Our previous studies have demonstrated the prominent effect of arsenic trioxide (ATO) in inhibiting the stemness of glioma stem cells (GSCs) by downregulating Notch signaling $[7,8]$. Raddeanin A (RA), an active extraction from the root of the traditional Chinese medicinal herb Anemone raddeana Regel [9], plays an important role in suppressing tumors (Fig. 1A). Xue et al. demonstrated that RA inhibited invasion and induced apoptosis in human gastric cancer cell lines, including BGC-823, SGC-7901 and MKN-28 [10]. Guan et al. reported that RA suppressed angiogenesis by inhibiting VEGFR2 signaling in human colorectal tumors [11]. However, the exact effect of RA on glioblastoma remains unclear.

Apoptosis and autophagy are involved in numerous pathological processes and affect each other [12]. Clinicians and researchers continually focus on ameliorating the prognosis of patients with malignancies by inducing the apoptosis of malignant cells $[13,14]$. Autophagy is a conserved pathway of lysosomal degradation, which is characterized by autophagosome formation [15]. The resulting catabolic process primarily functions to refuel cells under conditions of dysfunctional metabolic building during a stressful stimulation [16]. However, under certain conditions, excessive autophagy may result in cell death, or apoptosis $[17,18]$. Accumulating evidence has demonstrated that resistance to apoptosis in cancer cells can be reversed by autophagy $[19,20]$.

ROS (reactive oxygen species) is primarily produced in the mitochondria [21] and has been associated with solid tumors [22]. Accumulating evidence suggests that cancer cells are usually under increased stressful conditions and are therefore more vulnerable to damage from further insults induced by anticancer drugs [23]. Furthermore, ROS can regulate various signaling pathways, including the mitogen-activated protein kinase (MAPK) signal transduction cascade [24]. c-Jun N-terminal kinase (JNK) is a member of the MAPK family, and is associated with the regulation of cell proliferation, survival and differentiation [25]. Recent studies have demonstrated that JNK is involved in mediating the apoptotic response of cells to pro-inflammatory cytokines and environmental stresses in most cases [26, 27]. Meanwhile, ROS has been demonstrated to be involved in the regulation of apoptosis [28] and the sustained phosphorylation of JNK (p-JNK) [24]. However, the relationship between RA and apoptosis in GBM as well as the involvement of ROS production and p-JNK remain unclear.

In the present study, we aim to elucidate the effect of RA on glioblastoma and its underlying molecular mechanisms.

\section{Materials and Methods}

Reagents and antibodies

RA with more than 98\% purity, confirmed by high-performance liquid chromatography (HPLC) was purchased from YuanMu Biotech (Shanghai, China). N-Acetyl-L-cysteine (NAC) and 3-Methyladenine (3MA) were purchased from Sigma-Aldrich (St. Louis, USA).

Cell lines and culture conditions

Human GBM cell lines (U251, U87, T98 and G112) were obtained from RIKEN Cell Bank (Tsukuba Science City, Japan). All cell lines were cultured in Dulbecco's modified Eagle medium (DMEM; HyClone, 


\section{Cellular Physiology Cell Physiol Biochem 2018;47:1108-1121 \begin{tabular}{c|c|c|} 
DOI: 10.1159/000490187 & $\begin{array}{l}\text { O } 2018 \text { The Author(s). Published by S. Karger AG, Basel } \\
\text { www.karger.com/cpb }\end{array}$
\end{tabular} \\ Peng et al.: Antitumor Effect of RA on Glioblastoma}

USA) supplemented with 10\% FBS (Excell Biology Inc., China) and 1\% penicillin/streptomycin solution (Gibco, USA), and were maintained in a humidified incubator containing $5 \% \mathrm{CO}_{2}$ at $37^{\circ} \mathrm{C}$.

\section{MTT assay}

Cells were seeded in 96 -well plates at a density of $5-8 \times 10^{4}$ cells $/ \mathrm{mL}$, followed by exposure to RA at the indicated concentrations (0-8 $\mu \mathrm{M})$ for different times (0-48 h). After adding $10 \mu \mathrm{L} /$ well of MTT solution $(5$ $\mathrm{mg} / \mathrm{mL}$ ), the dishes were incubated at $37^{\circ} \mathrm{C}$ for $4 \mathrm{~h}$. Next, formazan crystals were solubilized using $150 \mu \mathrm{L} /$ well DMSO, and absorbance was measured at $570 \mathrm{~nm}$ by a microplate reader (M200; TECAN, Switzerland).

\section{Wound healing assay}

For the assessment of migration, $1 \times 10^{5}$ cells were seeded in $3.5-\mathrm{cm}$ dishes and cultured until they reached $90 \%$ confluence. A wound was made by manually scratching the monolayer with a sterilized $200-$ $\mu \mathrm{L}$ pipette tip, and then the medium was replaced with fresh DMEM supplemented with $0.5 \%$ FBS. Cell migration into the wound was observed in nine random microscopic fields for each drug concentration and time point using a digital imaging system (DP21; Olympus, Japan).

\section{Transwell assay}

The invasive and migratory capacities of glioma cells were investigated by Transwell assay as previously described [29]. Cells were seeded in 24-well plates with 8- $\mu$ m pore Transwell chambers (Corning, USA). The membrane was coated with $80 \mu \mathrm{L}$ Matrigel (BD) to measure invasiveness or no Matrigel to measure migration. For the invasion assay, $5 \times 10^{4}$ cells suspended in serum-free DMEM were seeded into the upper chamber, and medium containing serum was added into the bottom chamber as a chemoattractant. For the migration assay, cells were suspended in serum-free medium and then added to the upper chamber, and medium without FBS was used in the bottom chamber. Following treatment, the cells with non-invasive or non-migratory capacities were swabbed. The invading and migrating cells that attached to the underside of the polycarbonate membrane surface were stained with $0.1 \%$ crystal violet for $30 \mathrm{~min}$, air-dried, washed, and then counted using a digital imaging system (DP21). Six random fields were selected, and the mean number of cells per field was calculated.

\section{Protein extraction and western blot analysis}

Protein extraction and western blotting were performed as previously described [30]. In brief, $3 \times 10^{5}$ cells were seeded in 6-cm dishes and exposed to RA (0-6 $\mu \mathrm{M})$ at different times. The protein concentration was determined using a BCA protein Assay Kit (Beyotime, China). Cell lysates containing total protein (20-120 $\mu \mathrm{g}$ ) were separated by SDS-PAGE and then transferred onto polyvinylidene difluoride (PVDF) membranes (Millipore, Germany) by the wet transfer method. Membranes were blocked with 5\% skim milk at room temperature and then incubated with the indicated primary antibodies against PARP-1 (sc-7150, Santa Cruz), Bax (sc-526, Santa Cruz), Bcl-2 (sc-492, Santa Cruz), caspase-3 (9661, Cell Signaling Technology), SQSTM1 (sc-25572, Santa Cruz), LC3 (L7543, Sigma-Aldrich), GAPDH (AC002, ABclonal Technology), $\beta$-actin (AC004, ABclonal Technology), JNK (9252, Cell Signaling Technology) or p-JNK (9255, Cell Signaling Technology) on a swing bed at $4{ }^{\circ} \mathrm{C}$ overnight. After washing three times with TBST, the blots were incubated with horseradish peroxidase (HRP)-conjugated secondary antibodies (ABclonal Technology) for $1 \mathrm{~h}$ on a swing bed at room temperature. Each immune complex was detected by Enhanced Chemiluminescence (ECL) Substrate (WESTAR Supernova, Cyanogen) and visualized by the ChemiDoc ${ }^{\mathrm{TM}}$ MP System (Bio-Rad).

\section{Morphological apoptosis}

Morphological changes induced by apoptosis were detected by Hoechst staining. After exposure to RA, cell slides were stained with Hoechst 33258 (Beyotime, China) for 5 min at room temperature. After washing, slides were observed using the FSX100 Bio Imaging Navigator (Olympus, Japan) to detect the morphology of chromatin and nuclei.

Transmission electron microscopy observation

Autophagosome formation was visualized by transmission electron microscopy (TEM) as previously described [31]. Cells $\left(1 \times 10^{5}\right.$ cells/well) were seeded in 6-well plates and allowed to attach. After treatment with RA for $24 \mathrm{~h}$, cells were trypsinized and then fixed with $2.5 \%$ glutaraldehyde in phosphate buffer 


\section{Cellular Physiology Cell Physiol Biochem 2018;47:1108-1121 \begin{tabular}{l|l} 
and Biochemistry Published online:May 30, 2018 & $\begin{array}{l}\text { (c) 2018 The Author(s). Published by S. Karger AG, Basel } \\
\text { www.karger.com/cpb }\end{array}$
\end{tabular}}

Peng et al.: Antitumor Effect of RA on Glioblastoma

overnight at $4{ }^{\circ} \mathrm{C}$. After a dehydrating step using ethanol and acetone, cells were post-fixed with $1 \%$ osmium tetroxide for $30 \mathrm{~min}$. Subsequently, the cells were infiltrated with araldite, polymerized, sectioned at a thickness of $60 \mathrm{~nm}$, and stained with lead citrate-uranyl acetate. Ultrathin sections were observed by a H-7650 transmission electron microscope (Hitachi, Japan).

\section{Annexin V-FITC and PI assay for flow cytometry}

The apoptotic rate of glioblastoma cells was detected using the Annexin V-FITC Apoptosis Detection Kit (BD Bioscience, USA) according to the manufacturer's instructions. Cells $\left(2 \times 10^{5}\right.$ cells $/$ well $)$ were seeded in 6-well dishes with the desired stimuli. The harvested cells were suspended in the $1 \mathrm{X}$ binding buffer, and stained using Annexin V-FITC and propidium iodide (PI) for $20 \mathrm{~min}$. Next, the treated cells were assessed using an Accuri C6 flow cytometer (BD Bioscience, USA).

\section{Measurement of ROS}

ROS levels were detected using a ROS kit (Beyotime, China) according to the manufacturer's instructions. Briefly, $5 \times 10^{5}$ cells were plated on Poly-D-lysine (PDL)-coated slides in 35-mm dishes. Following complete attachment, the cells were treated with the desired stimuli for $24 \mathrm{~h}$. Next, the cells were harvested and stained with $10 \mu \mathrm{M}$ DCFH-DA for $20 \mathrm{~min}$ at $37^{\circ} \mathrm{C}$. The slides were washed three times with DMEM free of FBS to thoroughly eliminate unconjugated probes, and were visualized using a FSX100 Bio Imaging Navigator (Olympus, Japan).

\section{Detection of caspase-3 activity}

Caspase-3 activity was detected using the Caspase-3 Activity Assay Kit (Beyotime, China) according to the manufacturer's instructions. Briefly, cell lysates were prepared after exposing cells to the desired stimuli. The activity of caspase-3 was measured using substrate the Ac-DEVD-pNA (acetyl-Asp-Glu-ValAsp $p$-nitroanilide). The release of pNA cleaved by caspase- 3 was quantified by measuring the absorbance at $405 \mathrm{~nm}$ using a microplate reader (M200; TECAN, Japan).

\section{Immunohistochemical staining}

In brief, 5 - $\mu$ m paraffin-embedded sections of tumor tissues were regularly deparaffinized and incubated in $\mathrm{H}_{2} \mathrm{O}_{2}$ for $10 \mathrm{~min}$. After washing, sections were microwaved and allowed to cool to room temperature. All primary antibodies were rabbit polyclonal antibodies: caspase-3 (9661, Cell Signaling Technology) and Ki67 (A2094, ABclonal). Cell slides were incubated with the primary antibodies at $4{ }^{\circ} \mathrm{C}$ overnight. Sections were incubated with the secondary antibody (PV6001, ZSGB-BIO) at $37^{\circ} \mathrm{C}$ for $30 \mathrm{~min}$ and rendered using the DAB kit (ZLI-9017, ZSGB-BIO) for 10 min. After intensive washing, slides were counterstained with hematoxylin for one minute. Subsequently, the slides were dehydrated, blocked and observed using Moticam 3000 (Motic, USA) at a high-power magnification (400X). All pictures were analyzed with Image-Pro Plus 6.0. The integral optical density (IOD) was selected, and six random high-power magnification fields were chosen for the mean value analysis to represent the relative protein expression levels.

\section{In vivo xenograft assay}

Approximately $3 \times 10^{6}$ cells were injected subcutaneously in the right flank of female BALB/c nude mice (15-20 g) purchased from Vital River Laboratory Animal Technology Co. Ltd. (Beijing, China). Mice were randomly assigned to the control group $(100 \mu \mathrm{L}$ of PBS without RA) or treatment groups ( $1 \mathrm{mg} / \mathrm{kg}$ or $2 \mathrm{mg} /$ $\mathrm{kg}$ body weight), and treated daily when tumors reached a palpable size of approximately $150 \mathrm{~mm}^{3}$. Tumor volumes were calculated by the standard formula of length $\times$ width ${ }^{2} / 2$. Animals were sacrificed when tumor volumes reached approximately $450 \mathrm{~mm}^{3}$. Tumors were removed and frozen in liquid nitrogen for routine western blotting or fixed in $4 \%$ formalin for routine immunohistochemistry analysis. All animal procedures were approved by the Animal Care and Ethical Committee of the First Affiliated Hospital of Harbin Medical University.

\section{Statistical analysis}

Data from independent experiments were expressed as the mean \pm SD. Statistical analysis between groups was performed using Student's $t$ test or one-way ANOVA as appropriate followed by multiple comparisons performed with a post hoc Bonferroni test (SPSS version 18.0). $P<0.05$ was considered statistically significant $(*)$. 


\section{Results}

$R A$ reduces GBM cell viability

To investigate the potential effect of RA on glioblastoma in vitro, four cultured GBM cell lines (G112, U87, U251 and T98) were exposed to the indicated concentrations of RA for $24 \mathrm{~h}$ or $48 \mathrm{~h}$. The MTT assay results demonstrated that RA significantly reduced cell viability in a dose- and timedependent manner relative to the DMSO-treated controls (Fig. 1B). These results indicate that RA inhibited the viability of GBM cells.

$R A$ inhibits the invasion and migration of GBM cells We next investigated whether RA exhibited antiinvasive and anti-migratory effects in GBM cells; thus, wound healing and Transwell assays were performed at different concentrations and time points. Following exposure to RA, the Transwell assays demonstrated that the cells presented considerably reduced invasive potential compared to the DMSO control group (Fig. 2A). Furthermore, RA-treated cells presented slower wound closure capacity than did the DMSO control group, as shown in Fig. 2B and $2 \mathrm{C}$. These results indicate that RA inhibited the migration and invasion of GBM in vitro.

\section{$R A$ induces apoptosis in GBM cells}

To determine whether apoptosis is responsible for the inhibition of GBM cell growth by RA, we conducted the Hoechst staining assay on U251 and T98 cells. Fig. 3A shows chromatin condensation and DNA fragmentation, which are morphological characteristics of apoptosis [32]. Furthermore, we used the Annexin V-FITC/PI double staining method and flow cytometry to examine the apoptotic rate. As shown in Fig. 3B, RA exposure for $24 \mathrm{~h}$ led to a significantly increased apoptotic rate in U251 and T98 cells. Furthermore, the western blotting results (Fig. 3C) demonstrated that treatment using $4 \mu \mathrm{M}$ RA for $24 \mathrm{~h}$, triggered

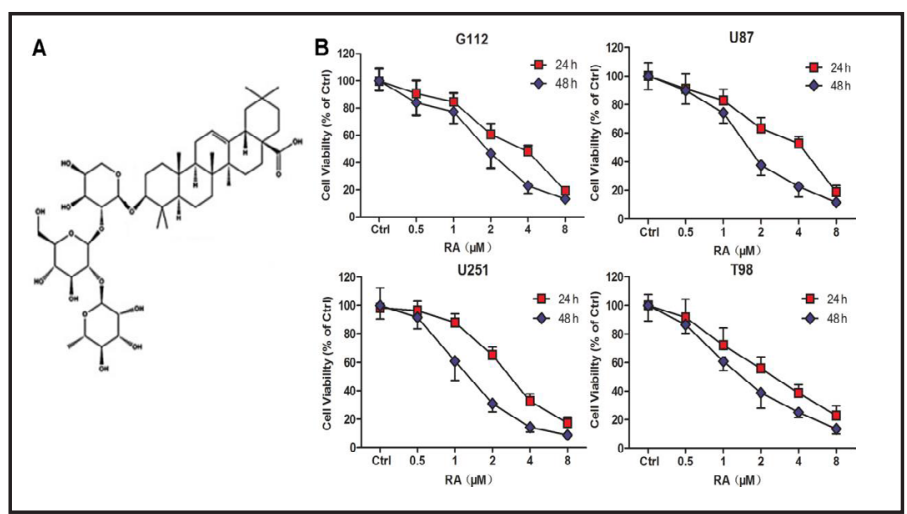

Fig. 1. Effect of RA on GBM cells. (A) Structure formula of RA. (B) Cell viabilities of human glioblastoma cell lines (G112, U87, U251, and T98) were measured after exposure to different concentrations of RA or $0.1 \%$ DMSO for different times. Data were normalized to $0.1 \%$ DMSO-treated control cells. Error bars represent SD (n=3). *, $\mathrm{P}<0.05$.

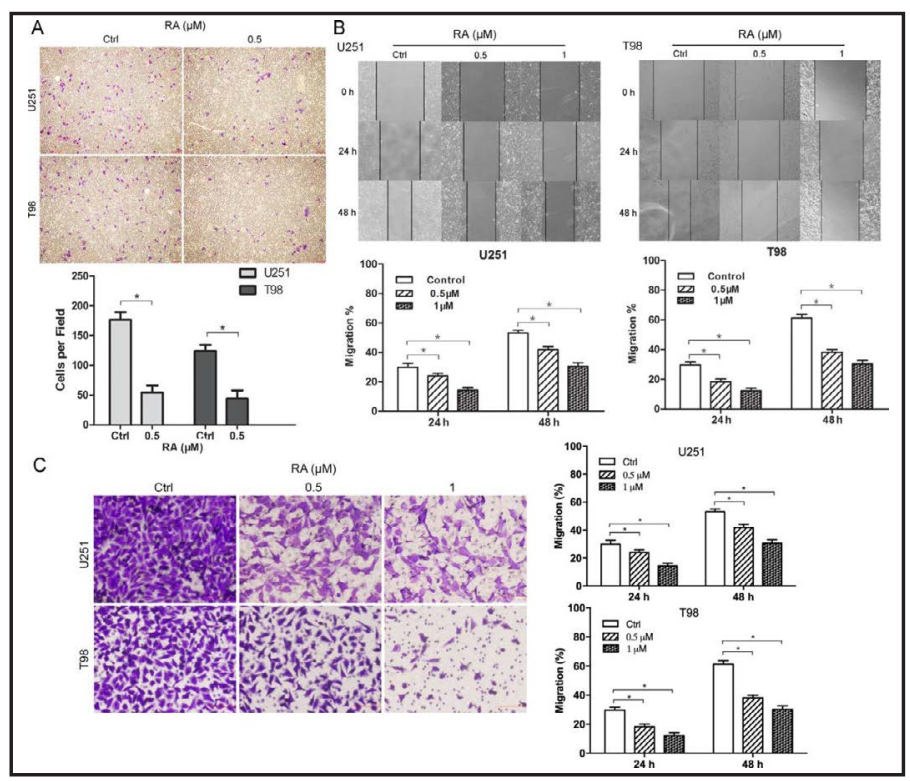

Fig. 2. Effect of RA on the invasive and migratory capacities of GBM cells. (A) Representative images and quantification of Transwell invasive ability of U251 and T98 cells. Magnification, 10X. (B) Representative images and quantification of the wound healing capacity of U251 and T98 cells. Magnification, 10X. (C) Representative images and quantification of the Transwell migratory ability of U251 and T98 cells. Magnification, 20X. Error bars represent SD (n=3). *, $\mathrm{P}<0.05$. 
apoptosis, and the levels of the key apoptosis activator cleaved caspase- 3 were increased. Full-length poly (ADP-ribose) polymerase 1 (PARP 1) is cleaved by caspase-3 from $116 \mathrm{kDa}$ into an $89 \mathrm{kDa}$ fragment [33]. As shown in Fig. 3C, PARP 1 cleavage was clearly detected in RA-treated GBM cells. Next, we observed that RA treatment increased the expression of proapoptotic Bax and decreased the level of anti-apoptotic Bcl-2 (Fig. 3C). To examine whether RA-induced apoptosis was caspase-dependent, we introduced the pan-caspase inhibitor z-VAD-fmk. As shown in Fig. 3D, combined treatment with z-VAD-fmk rescued RA-induced cell death. Lower activation of caspase- 3 and PARP 1 cleavage in the combined group were detected compared to that observed in groups that received RA treatment alone (Fig. 3E). Collectively, these results indicate that RA induced apoptotic cell death in GBM cells.

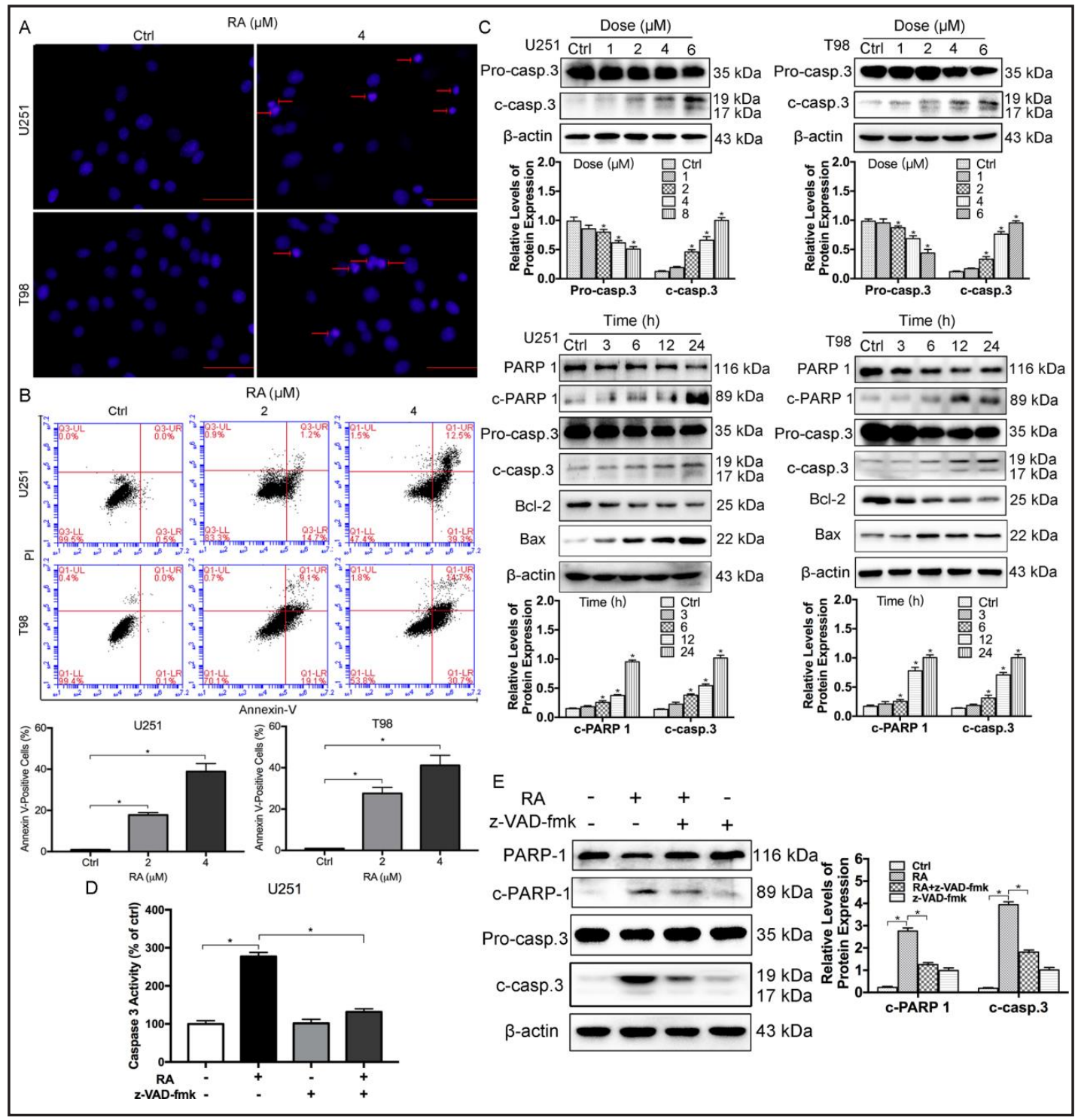

Fig. 3. Effect of RA on the induction of apoptosis signaling in GBM cells. The data demonstrated the effect of RA with or without $3 \mathrm{~h}$ of pretreatment with the pan-caspase inhibitor, z-VAD-fmk $(20 \mu \mathrm{M})$ on U251 and T98 cells. (A) Morphological changes induced by apoptotic cell death were detected by Hoechst staining. Bar: 50 $\mu \mathrm{m}$. (B) The apoptotic cells were calculated from Annexin V/FITC-positive cells (LR) detected by flow cytometry. (C) Levels of apoptosis-related proteins (caspase-3, PARP1, Bcl-2, and Bax) were detected by western blotting. (D) Activity of caspase-3 was measured by the substrate peptides Ac-DEVD-pNA. (E) Protein levels of caspase-3 and PARP1 were detected by western blotting. Error bars represent SD (n=3). * $\mathrm{P}<0.05$. 


\section{Cellular Physiology Cell Physiol Biochem 2018;47:1108-1121 \begin{tabular}{l|l} 
DOI: 10.1159/000490187 & O 2018 The Author(s). Published by S. Karger AG, Basel \\
www.karger.com/cpb
\end{tabular} Peng et al.: Antitumor Effect of RA on Glioblastoma}

ROS/JNK signaling is involved in RA-induced apoptosis in GBM cells

As RA induced cell death by apoptosis activation in cultured cells, we next investigated the underlying molecular mechanisms of apoptosis in cultured cells. ROS has been demonstrated to be involved in the regulation of apoptosis [28], and under stressful conditions, sustained JNK phosphorylation correlates with apoptosis [24,25]. Consistent with previous studies, our results demonstrated that RA treatment could lead to the massive production of intracellular ROS (Fig. 4A), and increase the level of p-JNK (Fig. 4B). Conversely, pretreatment with the antioxidant NAC ( $5 \mathrm{mM}$ ) could rescue cell viability by scavenging ROS (Fig. 4C and 4D). Next, the flow cytometry results (Fig. 4E) demonstrated that the ROS scavenger NAC significantly decreased the RA-induced apoptotic rate in GBM cells. In addition, we observed that caspase-3

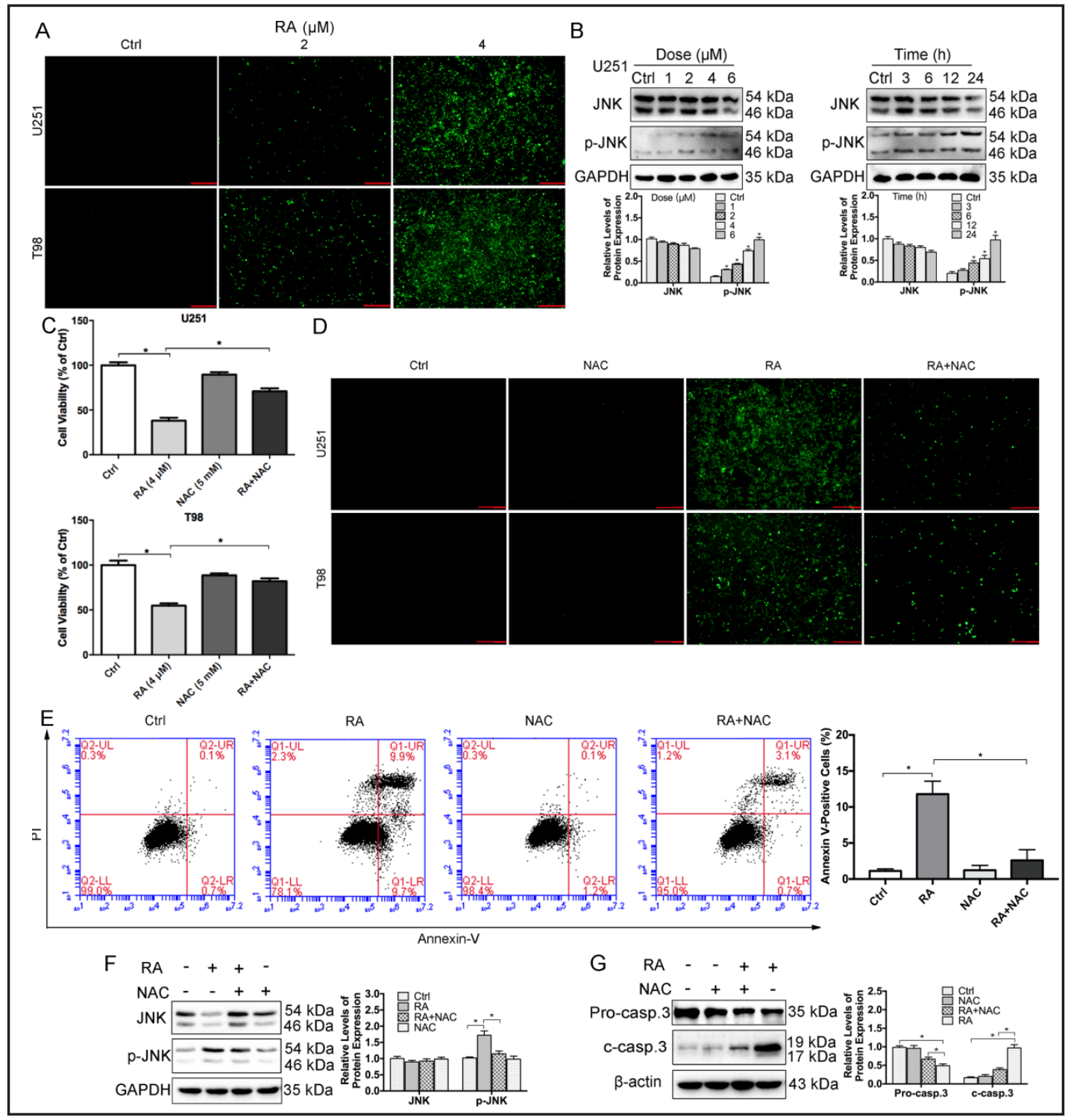

Fig. 4. Role of ROS/JNK signaling in RA-induced apoptosis in GBM cells. Cells were exposed to RA for $24 \mathrm{~h}$, with or without a $3 \mathrm{~h}$ pretreatment with the ROS scavenger, NAC (5 mM). (A, D) Representative micrographs of ROS production detected by DCFH-DA $(10 \mu \mathrm{M})$. Bar: $161 \mu \mathrm{m}$. (B) Levels of JNK and p-JNK were detected by western blotting. (C) Cell viability was detected by MTT assay. (E) Apoptotic cells were examined by flow cytometry. (F, G) Levels of JNK phosphorylation and caspase-3 activation were detected by western blotting. Error bars represent SD $(\mathrm{n}=3)$. * $\mathrm{P}<0.05$. 
activation was inhibited by the NAC treatment (Fig. 4G). Next, we examined changes in p-JNK in response to the combination of NAC and RA to investigate the involvement of ROS/JNK signaling in RA-induced apoptosis. As shown in Fig. 4F, after eliminating ROS by NAC, the levels of p-JNK in the combined treatment group with NAC were much lower than those observed in the U251 and T98 cells that received RA alone. Together, these results indicate that RA-triggered apoptosis in GBM cells was dependent on ROS/JNK signaling.

RA induces autophagy in GBM cells, and the suppression of autophagy enhances RAinduced apoptosis

To determine whether other cell death pathways are involved in GBM cells receiving RA treatment, we investigated the level of autophagy, which is regarded as type II programmed cell death [34]. The TEM results (Fig. 5A) demonstrated that after exposure to RA, autophagosomes were clearly observed, as indicated by the red arrows. The conversion of microtubule-associated protein light chain 3 I (LC3-I) to LC3-II serves as a marker for the

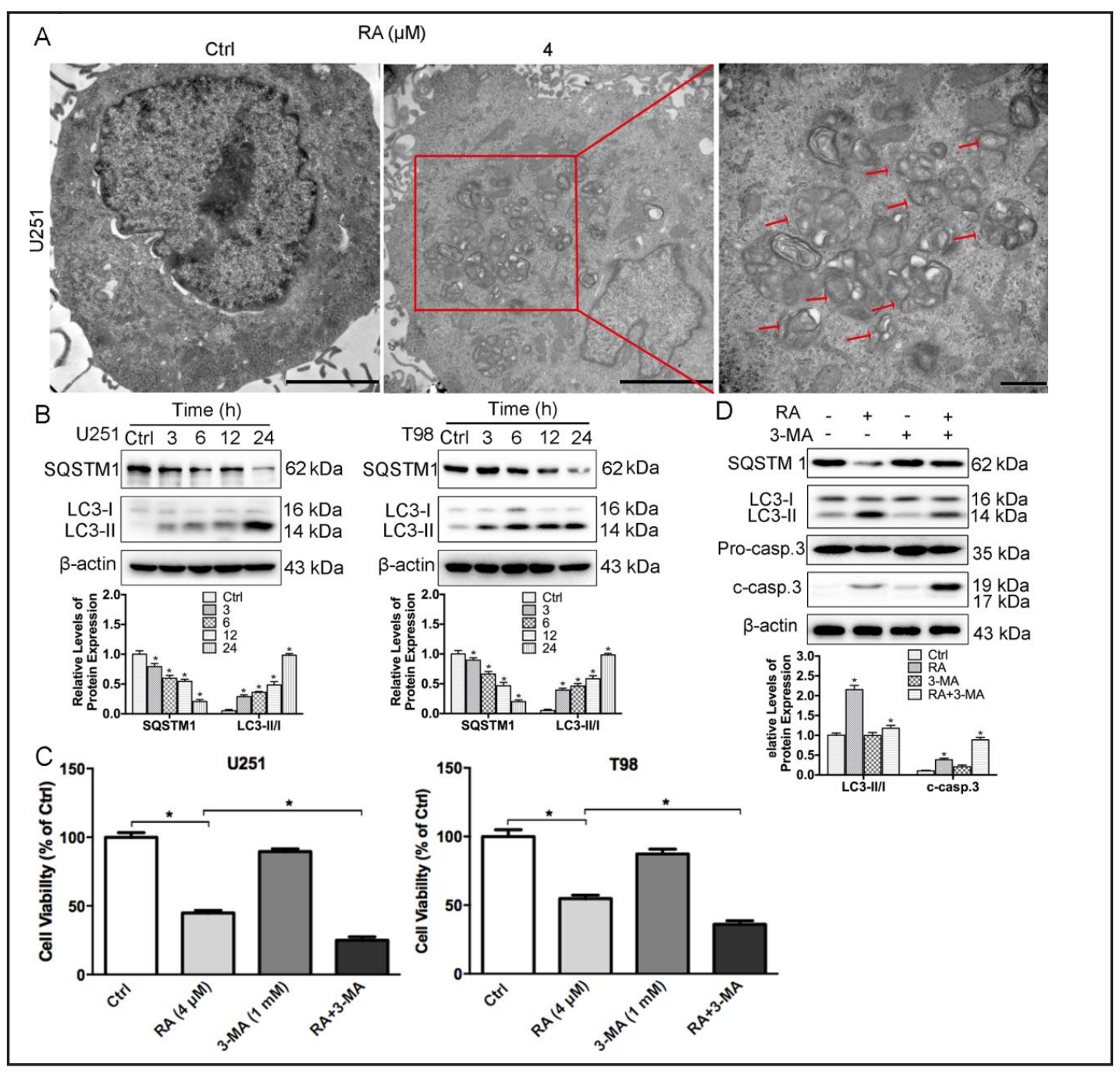

Fig. 5. Role of RA-induced autophagy in GBM cells. Cells were treated with RA for $24 \mathrm{~h}$, with or without a 3 $\mathrm{h}$ pretreatment with the autophagy inhibitor, 3-MA (1 mM) (A) Representative images of autophagosome formation in U251 cells detected by TEM, as indicated by the red arrows. Bar: $2 \mu \mathrm{m}$. (B) Levels of LC3 and SQSTM1 measured by western blotting. (C) Cell viability and efficiency of autophagy inhibition were detected by MTT assay. (D) Levels of SQSTM1, LC3 II, and caspase-3 in U251 cells were examined by western blotting. Error bars represent SD $(n=3)$. * $\mathrm{P}<0.05$.

\section{KARGER}


activation of autophagy signaling [35], and SQSTM1, an autophagic substrate, is degraded during the autophagic process [36, 37]. As shown in Fig. 5B, the level of LC3-II in U251 and T98 cells increased and was accompanied by the degradation of SQSTM1. Overwhelming evidence suggests that autophagy is a double-edged sword in carcinogenesis, either preventing tumor initiation or sustaining tumor metabolism [38]. To confirm the exact role of RA-induced autophagy in GBM cells, we examined cell viability in the presence or absence of an inhibitor of class III PI3K, 3-MA [31,35], which is a commonly used autophagy inhibitor. Interestingly, inhibition of autophagy exacerbated glioma cell death (Fig. 5C). As expected, the level of cleaved caspase- 3 was up-regulated after the inhibition of autophagy. Thus, U251 cell fate tend to shift toward apoptosis (Fig. 5D). Together, these results reveal that the inhibition of RA-induced autophagy enhanced apoptosis in GBM cells.

\section{RA inhibits GBM growth in vivo}

To verify the efficacy of RA in vivo, we performed tumor xenografts in the nude mouse model. The average tumor weight and volume in the RA-treated groups decreased after 7 days compared to that of the PBS-treated group (Fig. 6A and 6B). RA simultaneously decreased the level of the key proliferation marker Ki67 in U251-derived xenografts (Fig. 6H). As expected, no obvious decrease in the body weights of any tumor-bearing mice was observed (Fig. 6C and 6D). Next, RA increased the activation of caspase- 3 , conversion of LC3-I to LC3II and phosphorylation of JNK (Fig. 6E, 6F and 6G) compared to the levels observed in the PBStreated group. Furthermore, i $\mathrm{mmunoh}$ is to che mical staining demonstrated that RA induced apoptosis in vivo by elevating the level of cleaved caspase-3 (Fig. 6H). Taken together, our in vivo studies further support the inhibitory roles of RA on GBM in vitro.

\section{Discussion}

Despite decades of efforts, GBM remains the greatest challenge in the neurosurgical field, as it exhibits refractory recurrence and a poor prognosis. Advanced therapeutic strategies require further exploration. Excessive growth and high infiltration are

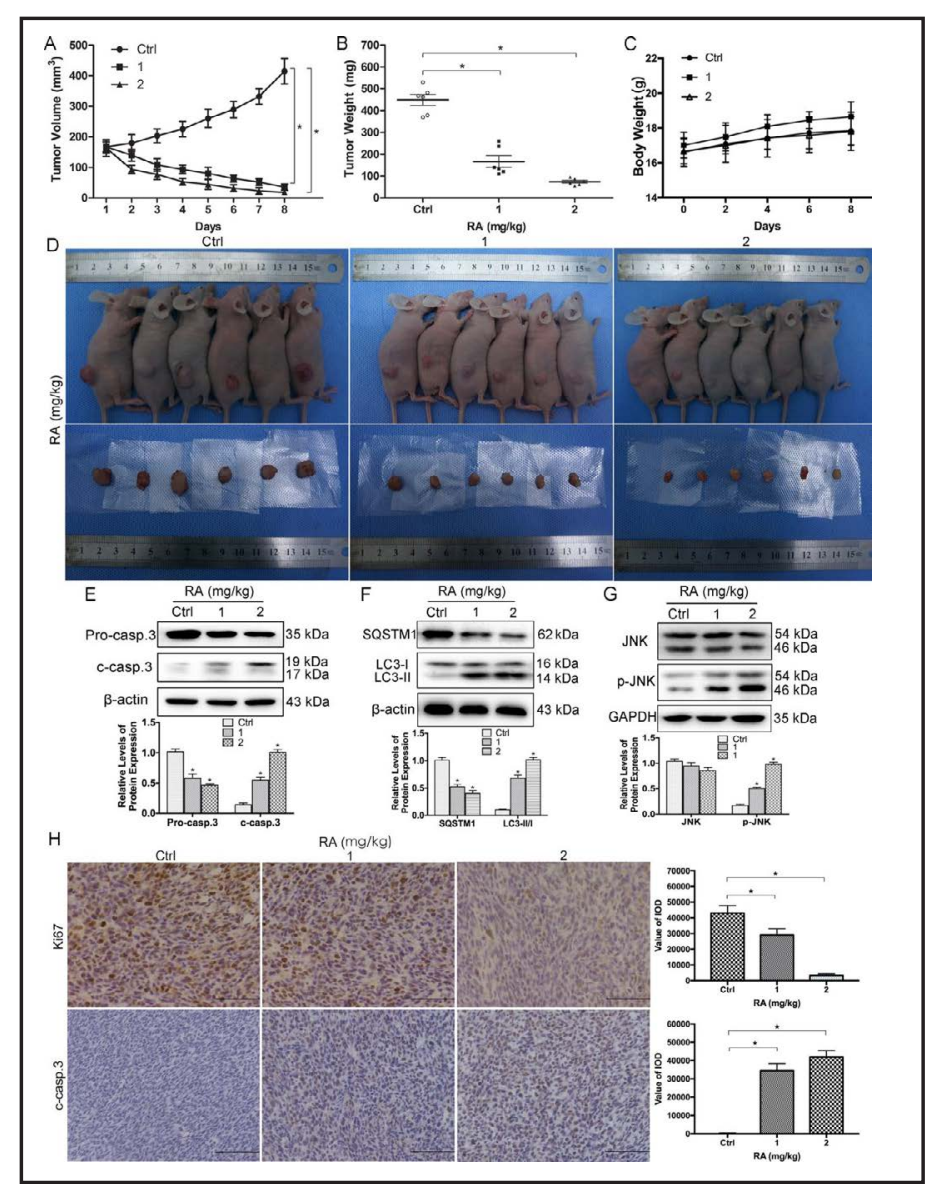

Fig. 6. Effect of RA on U251-derived xenografts in vivo. (A-C) Tumor volumes, tumor weights, and body weights were measured after intraperitoneal injection of RA or PBS. (D) General photographs of tumor-bearing mice assignment and tumor tissues. (E-G) Levels of caspase-3, LC3, SQSTM1, and p-JNK in U251-derived xenografts were detected by western blotting. (H) Levels of Ki67 and cleaved caspase- 3 were detected by immunohistochemical staining. Bar: 50 $\mu \mathrm{m}$. Error bars represent SD (n=3). *, $\mathrm{P}<0.05$. 


\section{Cellular Physiology Cell Physiol Biochem 2018;47:1108-1121 \begin{tabular}{ll|l} 
DOI: 10.1159/000490187 & O 2018 The Author(s). Published by S. Karger AG, Basel \\
www.karger.com/cpb
\end{tabular} Peng et al.: Antitumor Effect of RA on Glioblastoma}

associated with glioma aggression and invasion, which are potential therapeutic targets for eradicating glioblastoma.

Tumor cells acquire growth signaling autonomy to attain limitless growth, which results in an imbalance of homeostasis [4]. Thus, regimens that can significantly impede the growth of GBM are in urgent need. RA exerts inhibitory effects on cell viability and induces apoptotic cell death in various cancer types [10, 11]. Consistent with those findings, our results demonstrated that RA markedly suppressed the viability of GBM cells (Fig. 1). Another well-known

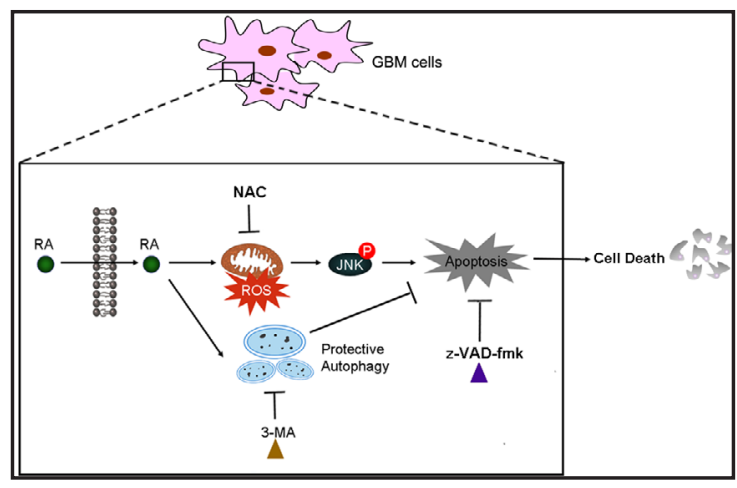

Fig. 7. Schematic diagram illustrates the relationship between autophagy and ROS/JNK-mediated apoptosis induced by RA exposure. characteristic of glioblastoma is the infiltration of adjacent normal brain parenchyma. Cells in the infiltrative region render the tumor surgically incurable and mediate post-operative recurrence of the primary tumor. Therefore, the invasion and migration of glioblastoma cells have become important research topics, and anti-invasive and anti-migratory treatment strategies will be highly valuable to GBM patients. Xue et al. demonstrated that RA inhibited migration and invasion in low differentiated human gastric cancer BGC-823 cell line in a dose dependent manner [10]. Our results showed that RA significantly reduced the invasive and migratory abilities of GBM cells (Fig. 2), demonstrating that RA could potentially improve the prognosis of GBM patients. Matrix metalloproteinases (MMPs) comprise a family of zinc-dependent endopeptidases that can degrade the extracellular matrix, thus promoting the invasion and metastasis of cancer cells [39]. Strong correlations have been reported between elevated levels of MMPs (MMP2 and MMP9) and tumor cell invasiveness in human gliomas [40]. However, invasion and metastasis in glioblastoma are multi-step processes with complex molecular mechanisms. Thus, further exploration of the effect of RA on MMPs in glioblastoma is required.

ROS plays a pivotal role in the maintenance of cell homeostasis. Nonetheless, several reports have demonstrated that excessive accumulation of intracellular ROS is usually associated with apoptosis in cancer cells $[41,42]$. Li et al. showed that RA exerted a synergistic effect with cisplatin on inducing ROS production in hepatocellular carcinoma [43]. Liu et al. reported that oxidative stress occurred after exposure to a concentration of $300 \mu \mathrm{M} \mathrm{H}_{2} \mathrm{O}_{2}$ and caspase-3-involved apoptosis was detected in the human glioma U251 cell line [44]. Consistent with previous studies, we observed that RA treatment triggered apoptosis signaling in GBM cells (Fig. 3). The Bcl-2 family plays a key role in apoptosis, in which Bax (proapoptotic gene) and Bcl-2 (anti-apoptotic gene) are influential factors for the downstream activation of caspase protein $[45,46]$. Consistently, we observed the downregulation of Bcl-2 and upregulation of Bax in a time-dependent manner after RA treatment. Intriguingly, the FACS results demonstrated that a small portion of PI-positive cells could be detected after RA exposure (Fig. 3B). Simultaneously, the inhibition of RA-induced apoptosis by z-VAD-fmk can partially rescue PI-positive cells as shown in Fig. 4E. Based on these findings, we conclude that RA induced cell death in glioblastoma cells occurs primarily but not exclusively via apoptosis. Other cell death signaling may be involved and requires further investigation.

MAPK signaling is frequently activated in several cancers and is responsible for apoptosis [47]. Baik et al. reported that cordycepin induced apoptosis through an extrinsic pathway and the activation of p38 MAPK in U87 cells [48]. Teng et al. demonstrated that p38 MAPK is activated during RA-induced apoptosis in the human gastric cancer SGC-7901 cell line [49]. Herein, massive ROS production induced by RA was observed in GBM cells using a DCFH-DA fluorescent probe. Similarly, we observed that sustained p-JNK, which is closely related to stressful stimuli, regulated RA-induced apoptosis in glioblastoma. Conversely, ROS scavenging by the antioxidant NAC partially rescued cell viability, inhibited p-JNK, and decreased caspase-3 activation (Fig. 4). 


\section{Cellular Physiology Cell Physiol Biochem 2018;47:1108-1121 \begin{tabular}{c|c|c|} 
DOI: 10.1159/000490187 & $\begin{array}{l}\text { O 2018 The Author(s). Published by S. Karger AG, Basel } \\
\text { www.karger.com/cpb }\end{array}$
\end{tabular} \\ Peng et al.: Antitumor Effect of RA on Glioblastoma}

Together, these results demonstrate that ROS/JNK signaling is involved in RA-induced apoptosis in GBM cells, and may provide potential strategies against malignant gliomas.

Autophagy represents an important cellular-physiologic response. The interplay between autophagy and apoptosis is complex and has been the focus of research [50,51].In most reports, autophagy has been demonstrated to protect cancer cells from apoptosis by providing nutrition and inducing resistance $[52,53]$. However, excessive autophagy can lead to caspase-independent cell death. Our results revealed that RA induced autophagy signaling (Fig. 5). Since autophagy plays dual roles during tumor progression, we inhibited autophagy by 3-MA. Interestingly, after blocking autophagy, the viability of U251 cells decreased in the combination therapy group, exhibiting increased apoptosis. These results indicate that autophagy may protect glioblastoma cells from RA-induced apoptosis and provide evidence for the combined use of RA and an autophagy inhibitor as a novel strategy for GBM therapy. The relationship between RA-induced apoptosis and autophagy is illustrated in Fig. 7.

$\mathrm{RA}$ is the primary ingredient of a famous Chinese patent medicine. Luan et al. developed a superior method for the analysis and quantification of RA in rat plasma by intravenous injection of a concentration of $0.75 \mathrm{mg} / \mathrm{kg}$ body weight [9]. Wang et al. investigated the plasma concentration of RA by injecting $0.5 \mathrm{mg} / \mathrm{kg}, 1.5 \mathrm{mg} / \mathrm{kg}$, and $4.5 \mathrm{mg} / \mathrm{kg}$ in mice. After 10 days, the RA injection was demonstrated to exert a significant inhibitory effect on tumor growth with an obvious dosage-effect relationship [54]. Thus, we chose intraperitoneal dosages of $1 \mathrm{mg} / \mathrm{kg}$ and $2 \mathrm{mg} / \mathrm{kg}$ to investigate the effects of RA on glioblastoma in vivo, and the results were consistent with our in vitro results. Nevertheless, the therapeutic use of RA in GBM patients may be warranted under a strict protocol in the future.

\section{Conclusion}

Our study demonstrated a novel anti-glioma effect of RA mediated by inducing the ROS/ JNK cascade in glioblastoma. The ROS/JNK cascade was involved in RA-induced apoptosis and contributed to RA-induced cell death. Moreover, apoptotic cell death could be enhanced by blocking RA-induced autophagy. To date, no remarkable progress has been made in the development of effective strategies for eliminating glioblastoma. Thus, the results of this study may shed new light on the understanding and treatment of glioblastoma.

\section{Abbreviations}

RA (Raddeanin A); GBM (glioblastoma multiforme); ACD (autophagic cell death); JNK (c-Jun N-terminal kinase); ATO (arsenic trioxide); GSCs (glioma stem cells); MAPK (mitogen-activated protein kinase); HPLC (high-performance liquid chromatography); NAC ( $N$-Acetyl-L-cysteine); 3-MA (3-methyladenine); DMEM (Dulbecco's modified Eagle medium); MTT (3-(4, 5-dimethylthylthiazol-2-yl) 2, 5-diphenyltetrazolium bromide); PMSF (phenylmethanesulfonyl fluoride); PVDF (polyvinylidene difluoride); HRP (horseradish peroxidase); ECL (enhanced chemiluminescence); PDL (poly-D-lysine); Ac-DEVD-pNA (acetyl-Asp-Glu-Val-Asp p-nitroanilide); BSA (bovine serum albumin); IOD (integral optical density); TEM (transmission electron microscopy); PI (propidium iodide); ROS (reactive oxygen species); PARP (1 poly (ADP-ribose) polymerase 1); LC3-II (microtubule-associated protein light chain 3-II).

\section{Acknowledgements}

We thank Chenguang Li (Neurosurgery of Second Affiliated Hospital of Zhejiang University) for assistance in proofreading the manuscript.

This study was primarily supported by the National Natural Science Foundation of China (Grant No. 81272788, 81472368, 81372701) and the First Affiliated Hospital of Harbin Medical University Foundation (Grant No. 2016B006). 


\section{Cellular Physiology Cell Physiol Biochem 2018;47:1108-1121 \begin{tabular}{l|l} 
DOI: 10.1159/000490187 & $\begin{array}{l}\text { O 2018 The Author(s). Published by S. Karger AG, Basel } \\
\text { www.karger.com/cpb }\end{array}$
\end{tabular} \\ Peng et al.: Antitumor Effect of RA on Glioblastoma}

\section{Disclosure Statement}

The authors declare that they have no conflicts of interest to disclose.

\section{References}

$>1$ Louis DN, Ohgaki H, Wiestler OD, Cavenee WK, Burger PC, Jouvet A, Scheithauer BW, Kleihues P: The 2007 WHO classification of tumours of the central nervous system. Acta Neuropathol 2007;114:97-109.

-2 Gilbert MR, Dignam JJ, Armstrong TS, Wefel JS, Blumenthal DT, Vogelbaum MA, Colman H, Chakravarti A, Pugh S, Won M, Jeraj R, Brown PD, Jaeckle KA, Schiff D, Stieber VW, Brachman DG, Werner-Wasik M, Tremont-Lukats IW, Sulman EP, Aldape KD, Curran WJ, Jr., Mehta MP: A randomized trial of bevacizumab for newly diagnosed glioblastoma. N Engl J Med 2014;370:699-708.

-3 Stupp R, Taillibert S, Kanner AA, Kesari S, Steinberg DM, Toms SA, Taylor LP, Lieberman F, Silvani A, Fink KL, Barnett GH, Zhu JJ, Henson JW, Engelhard HH, Chen TC, Tran DD, Sroubek J, Tran ND, Hottinger AF, Landolfi J, Desai R, Caroli M, Kew Y, Honnorat J, Idbaih A, Kirson ED, Weinberg U, Palti Y, Hegi ME, Ram Z: Maintenance Therapy With Tumor-Treating Fields Plus Temozolomide vs Temozolomide Alone for Glioblastoma: A Randomized Clinical Trial. JAMA 2015;314:2535-2543.

4 Hanahan D, Weinberg RA: Hallmarks of cancer: the next generation. Cell 2011;144:646-674.

5 Patel AP, Tirosh I, Trombetta JJ, Shalek AK, Gillespie SM, Wakimoto H, Cahill DP, Nahed BV, Curry WT, Martuza RL, Louis DN, Rozenblatt-Rosen O, Suva ML, Regev A, Bernstein BE: Single-cell RNA-seq highlights intratumoral heterogeneity in primary glioblastoma. Science 2014;344:1396-1401.

6 Jelassi B, Anchelin M, Chamouton J, Cayuela ML, Clarysse L, Li J, Gore J, Jiang LH, Roger S: Anthraquinone emodin inhibits human cancer cell invasiveness by antagonizing P2X7 receptors. Carcinogenesis 2013;34:1487-1496.

7 Zhen Y, Zhao S, Li Q Li Y, Kawamoto K: Arsenic trioxide-mediated Notch pathway inhibition depletes the cancer stem-like cell population in gliomas. Cancer Lett 2010;292:64-72.

$>8$ Wu J, Ji Z, Liu H, Liu Y, Han D, Shi C, Shi C, Wang C, Yang G, Chen X, Shen C, Li H, Bi Y, Zhang D, Zhao S: Arsenic trioxide depletes cancer stem-like cells and inhibits repopulation of neurosphere derived from glioblastoma by downregulation of Notch pathway. Toxicol Lett 2013;220:61-69.

-9 Luan X, Guan YY, Wang C, Zhao M, Lu Q, Tang YB, Liu YR, Yu DH, Wang XL, Qi H, Fang C, Chen HZ: Determination of Raddeanin A in rat plasma by liquid chromatography-tandem mass spectrometry: application to a pharmacokinetic study. J Chromatogr B Analyt Technol Biomed Life Sci 2013;923-924:4347.

10 Xue G, Zou X, Zhou J-Y, Sun W, Wu J, Xu J-L, Wang R-P: Raddeanin A induces human gastric cancer cells apoptosis and inhibits their invasion in vitro. Biochem Biophys Res Com 2013;439:196-202.

11 Guan YY, Liu HJ, Luan X, Xu JR, Lu Q, Liu YR, Gao YG, Zhao M, Chen HZ, Fang C: Raddeanin A, a triterpenoid saponin isolated from Anemone raddeana, suppresses the angiogenesis and growth of human colorectal tumor by inhibiting VEGFR2 signaling. Phytomedicine 2015;22:103-110.

-12 Maiuri MC, Zalckvar E, Kimchi A, Kroemer G: Self-eating and self-killing: crosstalk between autophagy and apoptosis. Nat Rev Mol Cell Biol 2007;8:741-752.

13 Fox JL, MacFarlane M: Targeting cell death signalling in cancer: minimising ‘Collateral damage'. Br J Cancer 2016;10.1038/bjc.2016.111

14 Ghobrial IM, Witzig TE, Adjei AA: Targeting apoptosis pathways in cancer therapy. CA Cancer J Clin 2005;55:178-194.

15 Yang Z, Klionsky DJ: Mammalian autophagy: core molecular machinery and signaling regulation. Curr Opin Cell Biol 2010;22:124-131.

16 He C, Klionsky DJ: Regulation mechanisms and signaling pathways of autophagy. Annu Rev Genet 2009;43:67-93.

17 Yuan J, Kroemer G: Alternative cell death mechanisms in development and beyond. Genes Dev 2010;24:2592-2602.

18 Denton D, Nicolson S, Kumar S: Cell death by autophagy: facts and apparent artefacts. Cell Death Differ 2012;19:87-95. 


\section{Cellular Physiology Cell Physiol Biochem 2018;47:1108-1121 \begin{tabular}{l|l|l} 
DOI: 10.1159/000490187 & O 2018 The Author(s). Published by S. Karger AG, Basel \\
www.karger.com/cpb
\end{tabular}}

Peng et al.: Antitumor Effect of RA on Glioblastoma

19 Kaza N, Kohli L, Roth KA: Autophagy in brain tumors: a new target for therapeutic intervention. Brain Pathol 2012;22:89-98.

-20 Mora R, Regnier-Vigouroux A: Autophagy-driven cell fate decision maker: activated microglia induce specific death of glioma cells by a blockade of basal autophagic flux and secondary apoptosis/necrosis. Autophagy 2009;5:419-421.

-21 Ray PD, Huang BW, Tsuji Y: Reactive oxygen species (ROS) homeostasis and redox regulation in cellular signaling. Cell Signal 2012;24:981-990.

-22 Reuter S, Gupta SC, Chaturvedi MM, Aggarwal BB: Oxidative stress, inflammation, and cancer: how are they linked? Free Radic Biol Med 2010;49:1603-1616.

-23 Pelicano H, Carney D, Huang P: ROS stress in cancer cells and therapeutic implications. Drug Resist Updat 2004;7:97-110.

24 Shen HM, Liu ZG: JNK signaling pathway is a key modulator in cell death mediated by reactive oxygen and nitrogen species. Free Radic Biol Med 2006;40:928-939.

25 Davis RJ: Signal transduction by the JNK group of MAP kinases. Cell 2000;103:239-252.

-26 Lei Y-Y, Wang W-J, Mei J-H, Wang C-L: Mitogen-Activated Protein Kinase Signal Transduction in Solid Tumors. Asian Pac J Cancer Prev 2014;15:8539-8548.

27 Davies C, Tournier C: Exploring the function of the JNK (c-Jun N-terminal kinase) signalling pathway in physiological and pathological processes to design novel therapeutic strategies. Biochem Soc Trans 2012;40:85-89.

-28 Fleury C, Mignotte B, Vayssiere JL: Mitochondrial reactive oxygen species in cell death signaling. Biochimie 2002;84:131-141.

-29 Tu Y, Gao X, Li G, Fu H, Cui D, Liu H, Jin W, Zhang Y: MicroRNA-218 inhibits glioma invasion, migration, proliferation, and cancer stem-like cell self-renewal by targeting the polycomb group gene Bmi1 Cancer Res 2013;73:6046-6055.

30 Hu P, Zhou H, Lu M, Dou L, Bo G, Wu J, Huang S: Autophagy Plays a Protective Role in Advanced Glycation End Product-Induced Apoptosis in Cardiomyocytes. Cell Physiol Biochem 2015;37:697-706.

-31 Li C, Liu Y, Liu H, Zhang W, Shen C, Cho K, Chen X, Peng F, Bi Y, Hou X, Yang Z, Zheng Z, Wang K, Wang X, Zhang J, Zhong C, Zou H, Zhang X, Zhao S: Impact of autophagy inhibition at different stages on cytotoxic effect of autophagy inducer in glioblastoma cells. Cell Physiol Biochem 2015;35:1303-1316.

32 Wong RS: Apoptosis in cancer: from pathogenesis to treatment. J Exp Clin Cancer Res 2011;30:87.

33 Lazebnik YA, Kaufmann SH, Desnoyers S, Poirier GG, Earnshaw WC: Cleavage of poly(ADP-ribose) polymerase by a proteinase with properties like ICE. Nature 1994;371:346-347.

34 de Bruin EC, Medema JP: Apoptosis and non-apoptotic deaths in cancer development and treatment response. Cancer Treat Rev 2008;34:737-749.

-35 Herman-Antosiewicz A, Johnson DE, Singh SV: Sulforaphane causes autophagy to inhibit release of cytochrome C and apoptosis in human prostate cancer cells. Cancer Res 2006;66:5828-5835.

36 Mizushima N, Levine B: Autophagy in mammalian development and differentiation. Nat Cell Biol 2010;12:823-830.

-37 Pankiv S, Clausen TH, Lamark T, Brech A, Bruun JA, Outzen H, Overvatn A, Bjorkoy G, Johansen T: p62/ SQSTM1 binds directly to Atg8/LC3 to facilitate degradation of ubiquitinated protein aggregates by autophagy. J Biol Chem 2007;282:24131-24145.

-38 White E: Deconvoluting the context-dependent role for autophagy in cancer. Nat Rev Cancer 2012;12:401410.

39 Egeblad M, Werb Z: New functions for the matrix metalloproteinases in cancer progression. Nat Rev Cancer 2002;2:161-174.

40 Nakada M, Okada Y, Yamashita J: The role of matrix metalloproteinases in glioma invasion. Front Biosci 2003;8:e261-269.

41 Dolado I, Swat A, Ajenjo N, De Vita G, Cuadrado A, Nebreda AR: p38alpha MAP kinase as a sensor of reactive oxygen species in tumorigenesis. Cancer Cell 2007;11:191-205.

42 Wang J, Yi J: Cancer cell killing via ROS: to increase or decrease, that is the question. Cancer Biol Ther 2008;7:1875-1884.

43 Li JN, Yu Y, Zhang YF, Li ZM, Cai GZ, Gong JY: Synergy of Raddeanin A and cisplatin induced therapeutic effect enhancement in human hepatocellular carcinoma. Biochem Biophys Res Commun 2017;485:335341. 


\section{Cellular Physiology Cell Physiol Biochem 2018;47:1108-1121

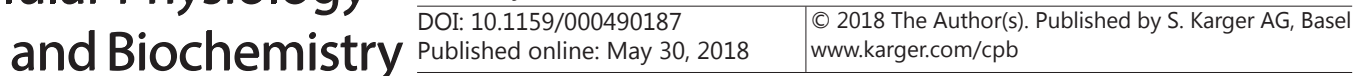 \\ Peng et al.: Antitumor Effect of RA on Glioblastoma}

44 Liu XR, Li YQ, Hua C, Li SJ, Zhao G, Song HM, Yu MX, Huang Q: Oxidative stress inhibits growth and induces apoptotic cell death in human U251 glioma cells via the caspase-3-dependent pathway. Eur Rev Med Pharmacol Sci 2015;19:4068-4075.

45 Reed JC: Regulation of apoptosis by bcl-2 family proteins and its role in cancer and chemoresistance. Curr Opin Oncol 1995;7:541-546.

-46 Yin C, Knudson CM, Korsmeyer SJ, Van Dyke T: Bax suppresses tumorigenesis and stimulates apoptosis in vivo. Nature 1997;385:637-640.

-47 Paiva C, Godbersen JC, Soderquist RS, Rowland T, Kilmarx S, Spurgeon SE, Brown JR, Srinivasa SP, Danilov AV: Cyclin-Dependent Kinase Inhibitor P1446A Induces Apoptosis in a JNK/p38 MAPK-Dependent Manner in Chronic Lymphocytic Leukemia B-Cells. PLoS One 2015;10:e0143685.

48 Baik JS, Mun SW, Kim KS, Park SJ, Yoon HK, Kim DH, Park MK, Kim CH, Lee YC: Apoptotic Effects of Cordycepin Through the Extrinsic Pathway and p38 MAPK Activation in Human Glioblastoma U87MG Cells. J Microbiol Biotechnol 2016;26:309-314.

49 Teng YH, Li JP, Liu SL, Zou X, Fang LH, Zhou JY, Wu J, Xi SY, Chen Y, Zhang YY, Xu S, Wang RP: Autophagy Protects from Raddeanin A-Induced Apoptosis in SGC-7901 Human Gastric Cancer Cells. Evid Based Complement Alternat Med 2016;2016:9406758.

50 Eisenberg-Lerner A, Bialik S, Simon HU, Kimchi A: Life and death partners: apoptosis, autophagy and the cross-talk between them. Cell Death Differ 2009;16:966-975.

-51 Nikoletopoulou V, Markaki M, Palikaras K, Tavernarakis N: Crosstalk between apoptosis, necrosis and autophagy. Biochim Biophys Acta 2013;1833:3448-3459.

52 Rodriguez CE, Reidel SI, Bal de Kier Joffe ED, Jasnis MA, Fiszman GL: Autophagy Protects from Trastuzumab-Induced Cytotoxicity in HER2 Overexpressing Breast Tumor Spheroids. PLoS One 2015;10:e0137920.

-53 Song B, Bian Q, Shao CH, Li G, Liu AA, Jing W, Liu R, Zhang YJ, Zhou YQ Hu XG, Jin G: Ulinastatin reduces the resistance of liver cancer cells to epirubicin by inhibiting autophagy. PLoS One 2015;10:e0120694.

54 Wang MK, Ding LS, Wu FE: Antitumor effects of raddeanin A on S180, H22 and U14 cell xenografts in mice. Ai Zheng 2008;27:910-913. 